\title{
THE EFFECT OF MOSAIC ON CELL STRUCTURE AND CHLOROPLASTS
}

\author{
Mervilie T. COOK
}

This is a continuation of previous studies, the results of: which were presented at the meeting of American Phytopathological Society, December 1926 and at the DesMoines Meeting of the same socieity in December 1929 and which have been published in the Journal of the Department of Agriculture of Puerto Rico (Vol. X Nos. $3 \& 4$, 1926 'and Vol. XIV, No. 2, 1930).

In the previous studies the writer called attention to two points in the reaction of the hosts to the disease. (1) The disease inhibits the development of the meristematic tissue so that there is very little or no differentiation after the virus comes in contact with it. (2) the inhibition of the chloroplasts for a time. These points have been discussed to a greater or less extent by other writers previous to my own studies. Woods (1902), Twanowski (1903), Melchers (1913), Doolittle (1920), Matsumota (1922), Rand (1922), Dickson (1922), Rawlins and Johnson (1925) and Goldstein (1926).

During the past year opportunity was offered to continue this work on other plants and it was thought desirable to do so, in order to determine if the laws held true in all cases.

The first plant for consideration at this time is the pepper which confirms in every detail the results of the writers studies on the tobaceo and tomato, except that the process is much more rapid which is in harmony with the growth of the plant. The pepper leaves open and attain full size more rapidly than either the tobacco or tomato and the leaves on the new shoots are much closer together.

These studies were made on several plants. Seven leaves were taken from the one selected for the drawing's. The first three did not show the mosaic pattern. The next showed a distinct pattern and in the sixth and seventh chlorotic areas were becoming green and the pattern indistinct. $A$ corresponding series of leaves were taken from a healthy plant.

The section of the first leaf showed an undifferentiated tissue, with very few small chloroplasts (Fig. 1). The second showed the formation of a palisade layer and a larger number of chloroplasts (Fig. 2) while the third showed that some of the palisade cells hal 
aivided which is an indication of a mild form of the disease (Fig. 3). The fourth showed practically the same conditions except that the chloroplasts contimued to increase in size and number (Fig. 4) and the mesophyll was slightly better developed. A series of four drawings made from the leaves of the normal plant (Figs. 5 to 8) showed that the youngest leaf was more advanced in cell and ehloroplast development than the second leaf from the diseased plants. The second leaf of the normal plant (Fig. 6) was better developed than the fourth leaf of the mosaic plant (Fig. 3). The third leat of the healthy plant (Fig. 7 ) was nearly equal to the fifth leaf of the diseased plant. The fourth leaf of the normal plant (Fig. 8) was better developed than the fifth leaf of the diseased plant. In general, it may be said that the results correspond to the results of my previous studies, although not so pronounced.

An cutlreak of the mosaic disease on Crotalaria striata gave the writer an opportunity to study the effects of the disease on this plant. A series of six leaves were taken from both diseased and tormal plants. The results are as follows:

The first and second leaves on all plants studied were unopened and of course did not show the symptoms of the disease. In the section of the first or very youngest leaf of a diseased plant it was possible to distinguish the areas that were to become chlorotic from those that were to become green (Figs. $9 \& 10$ ). In the section from the chlorotic areas, the cells were undifferentiated and tise chloroplasts few and small (Figs. 9\& 10) while in the sections from the areas that would have become green the palisade was slightly developed and the chloroplasts much more numerous and larger. These two drawings (Figs. $9 \& 10$ ) were made from a single section of a leaf. The third leaf of the diseased plants was not open and there was no visible pattern. Two sections from its leaf of the mosaic plant showed an increase in thickness, slight advance in cell structure which was greater in the section from the green arcat (Fig. 12) than in the section from the chlorotic area (Fig. 11) and a much greater development of chloroplasts in the green than in the chlorotic area. The development of hoth cell structure and chloroplasts was more advanced in the corresponding leaf from the normal plant than from the green area of the diseased plant.

The seventh leaf of the mosaic plant was open and the pattern distinct. The section (Fig. 13) from the chlorotic area was thin, the palisade very poorly developed, the mesophyll open, the chlornplasts few. and about normal in size when compared with the chloro- 
plasts of the normal leaf. (Fig. 14). The section (Fig. 15) from the green area of the diseased leaf was thicker but the cell structure showed the effects of the disease in the porly developed palisade. The chloroplasts were more numerous than in the chlorotic section (Fig. 13) but fewer than in the section from the normal leaf (Fig. 14). The ninth leaf of the diseased plant (Fig. 16) was thin, the palisade almost undeveloped but the ehloroplasts were larger and more normal. The section from the green area was almost normal in every particular.

The papaya (Carica papaya L.) is a plant of the tropies and near tropics. A few years ago I noticed a disease of this plant on the station grounds, but the gardener destroyed it before I had tirue to study it. This or a similar disease was reported later by Dr. Ciferri of Santo Domingo under the name of eurly leaf. Both Dr. Ciferri and myself are in doubt as to the exact cause of this disease but $\mathrm{I}$ am inclined to believe that it is due to a virus. A coniparison of a section of a very young diseased leaf (Fig. 17) with a section of a very young normal leaf (Fig. 18) shows that the diseased leaf is thimner than the normal leaf and that the palisade is not so well developed. Passing to the fifth leaf of the diseased plant (Fig. 19) and the fifth leaf of the normal plant (Fig. 20) we find that the diseased leaf is about one-half as thick as normait leaf and not so well developed. The chloroplasts of the diseased leaf at this stage are almost equal to the ehloroplasts of the normal leaf.

Two monocotyledonous plants were studied. The Amazon lily (Eucharist amazonica) and a hybrid Amarillis. The results of the studies on these plant's were so nearly the same that drawings were made from the first one. It was impossible at the time this material was collected to find any plants that were not diseased. Therefore the sections are made from the chlorotic and the green areas of diseased leaves. These plants produce two or three leaves in rapid succession and then re'st for a few months lefore producing mother cluster. Two clusters are usually to be found on a plant. The material from which these studies were made was collected irrmediately following the unfolding of the youngest leaf of a new cluster and was from the three young and two old leaves.

The section from the chlorotic area of the youngest leaf was thinner than the section from the green area and without chloroplasts. The section from the green area of the same leaf showed many small chloroplasts (Figs. $21 \& 22$ ). The sections from next leaf were 
thicker than those from the first leaf but the one from the chlorotie areas was thimner than the one from the green area. Both sections showed chloroplasts but they were more numerous in the thick than in the thin area (Figs. $23 \& 24$ ). "In the third leaf both areas were thin but the section from the green area showed a higher development in that there were numerous intercellular space's. Also the chloroplasts in the green area were larger and more numerous than in the ehlorotic area (Figs $25 \& 26$ ).

The two older leaves were less succulent than the three young leaves and the section's showed that they were thinner. In both old leaves the sections showed more chloroplasts in the green than in the chlorotic areas but for some unexplained reason those of the green areas were slightly smaller than those from the third leaf of the new cluster.

\section{EXPLANATION ON PLATES}

Fig. 1.-Section from youngest leaf of mosaic pepper.

Fig. 2:-Section from second leaf of same plant.

Fig. 3.-Section from the third leaf of the same plant. Note the divisions in three of the palisade cells which indicates a mild form of the disease and the increase in number and size of chlorcplasts which is probably the result of age and exposure to sunlight.

Fig. 4.-Section from the fourth leaf. Note that palisade is not so well developed as in the normal leaf (Fig. 8). Also note the increase in the size of the chloroplasts as compared with Fig. 3.

Figs. 5 to 8 .- Sections from the four youngest leaves of a healthy plant for comparison with the corresponding leaves of the diseased plant (Figs. 1 to 4 ).

Figs. 9 \& 10.-Sections from the chlorotic areas of a young leaf of a mosaic plant of Crotalaria striata. Note that Fig. 10 is better developed than Fig. 9.

Fig. 11.-Section from the chlorotic area of the next older leaf of the same plant.

Fig. 12.-Section from the green area of the same leaf. Note the greater development in both cells and chloroplasts.

Fig. 13.- Section from the chlorotic area of the seventh leaf of the same plant.

Fig. 14.-Section from the seventh leaf of a healthy plant.

Fig. 15.-Section from the green area of the same leaf as Fig. 18

Fig. 16.-Section from the chlorotic area of the ninth leaf of the diseased plant. 
EFTECT OF MOSAIC ON CELL STRUCTURE AND CHLOROPLAST 181

Fig. 17.-Section from a very young diseased leaf of Papaya carica.

Fig. 18.-Section from corresponding leaf of a healthy plant.

Fig. 19.-Section from an older leaf of a diseased plant.

Fig. 20.-Section from a corresponding leaf of a healthy plant.

Figs. 21, $23 \& 25$.-Sections from the chlorotic areas of a diseased plant of Eucharist amazonica.

Figs. 22., 24 and 26.--Sections from the green areas of the same leaves. 
PLATE IX.
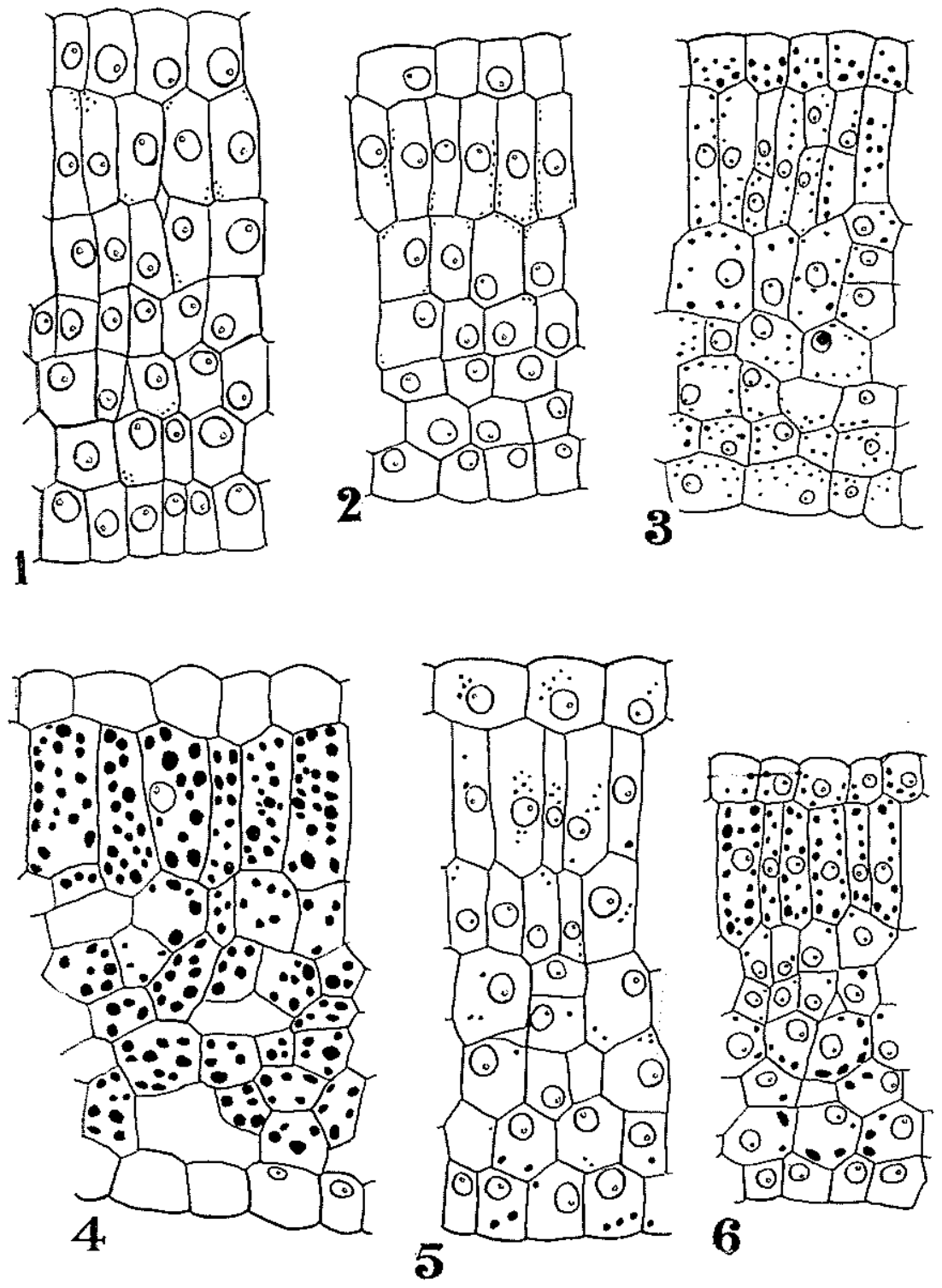

6 
PLATE X.

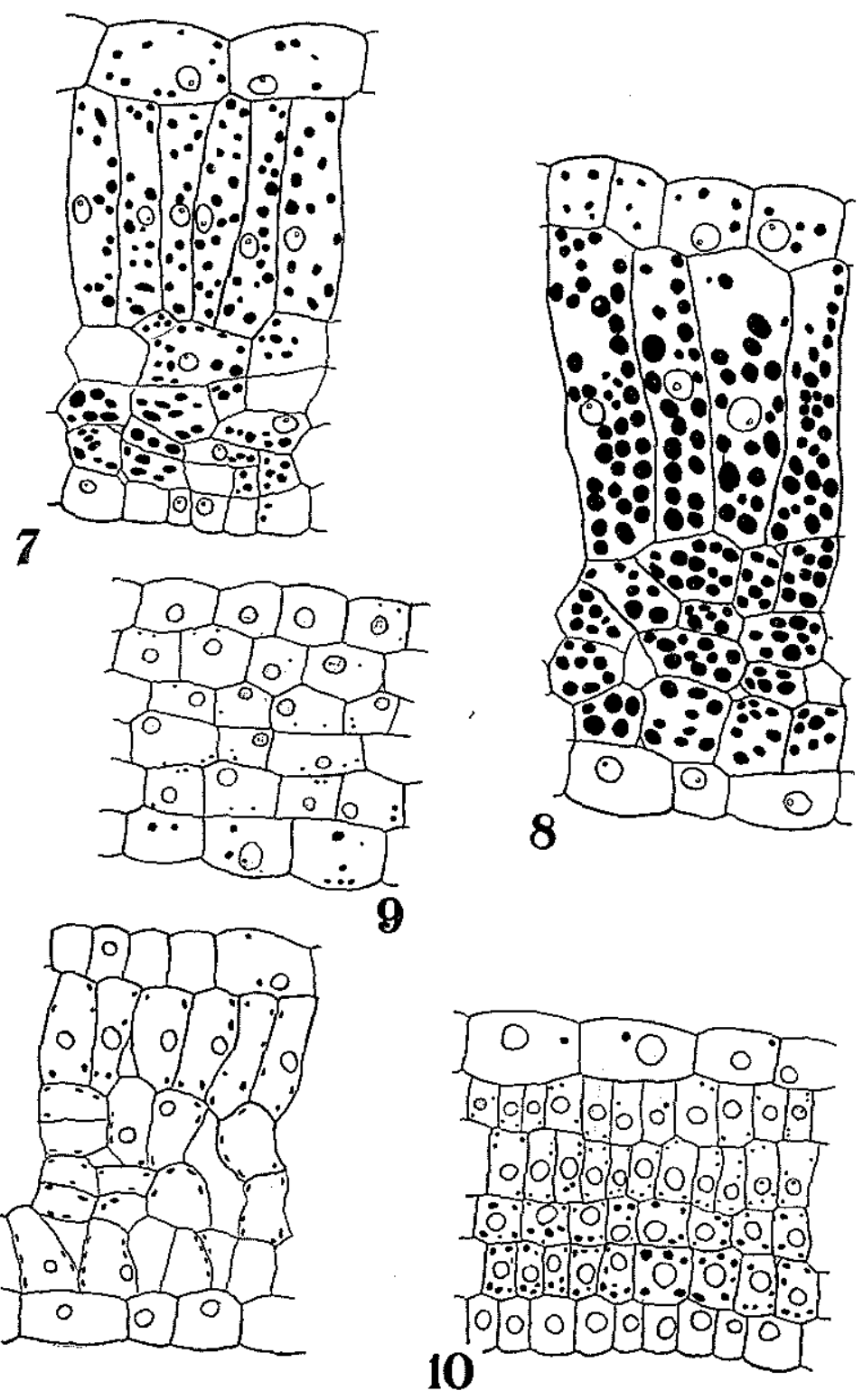


PLATE XI.

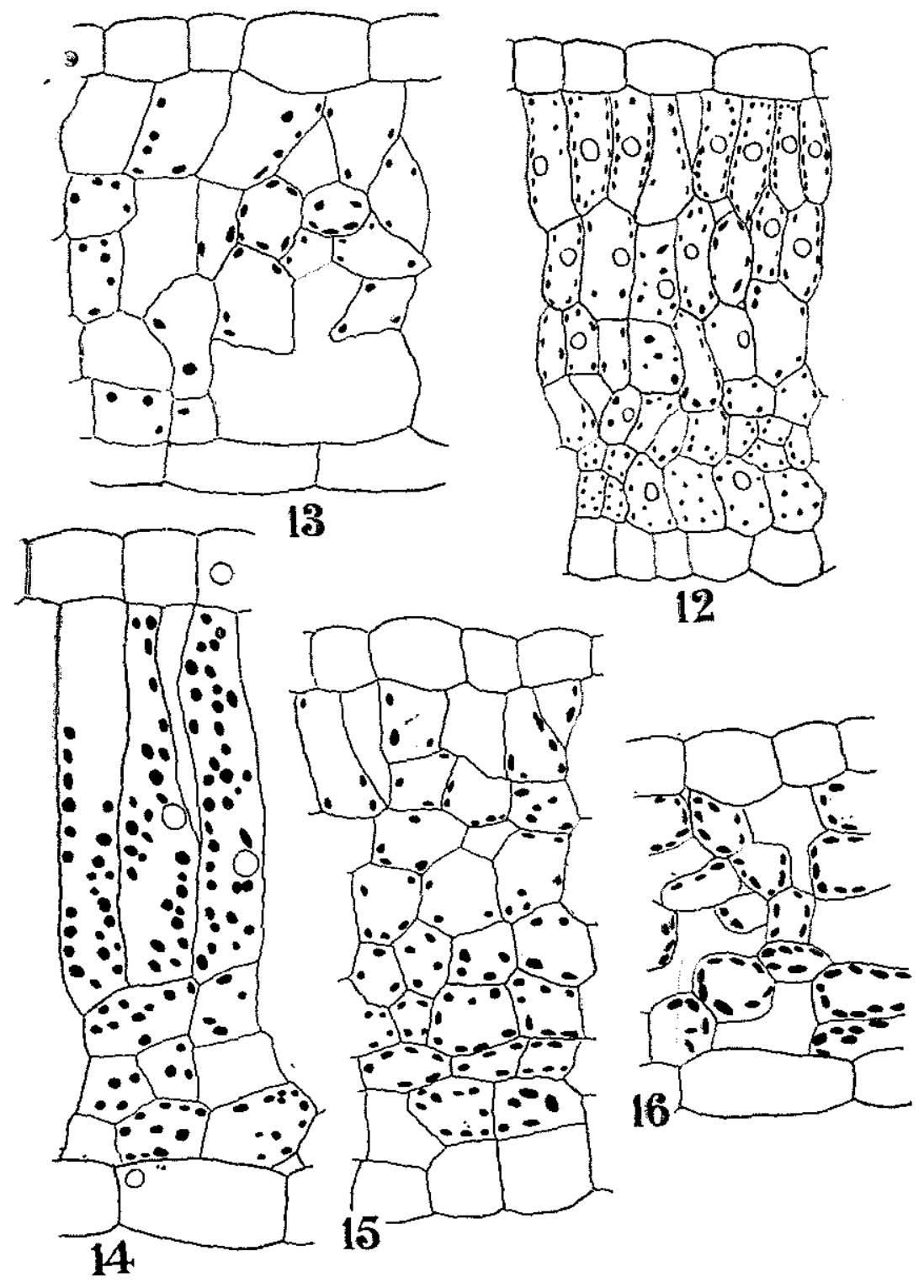


PLATE XII.
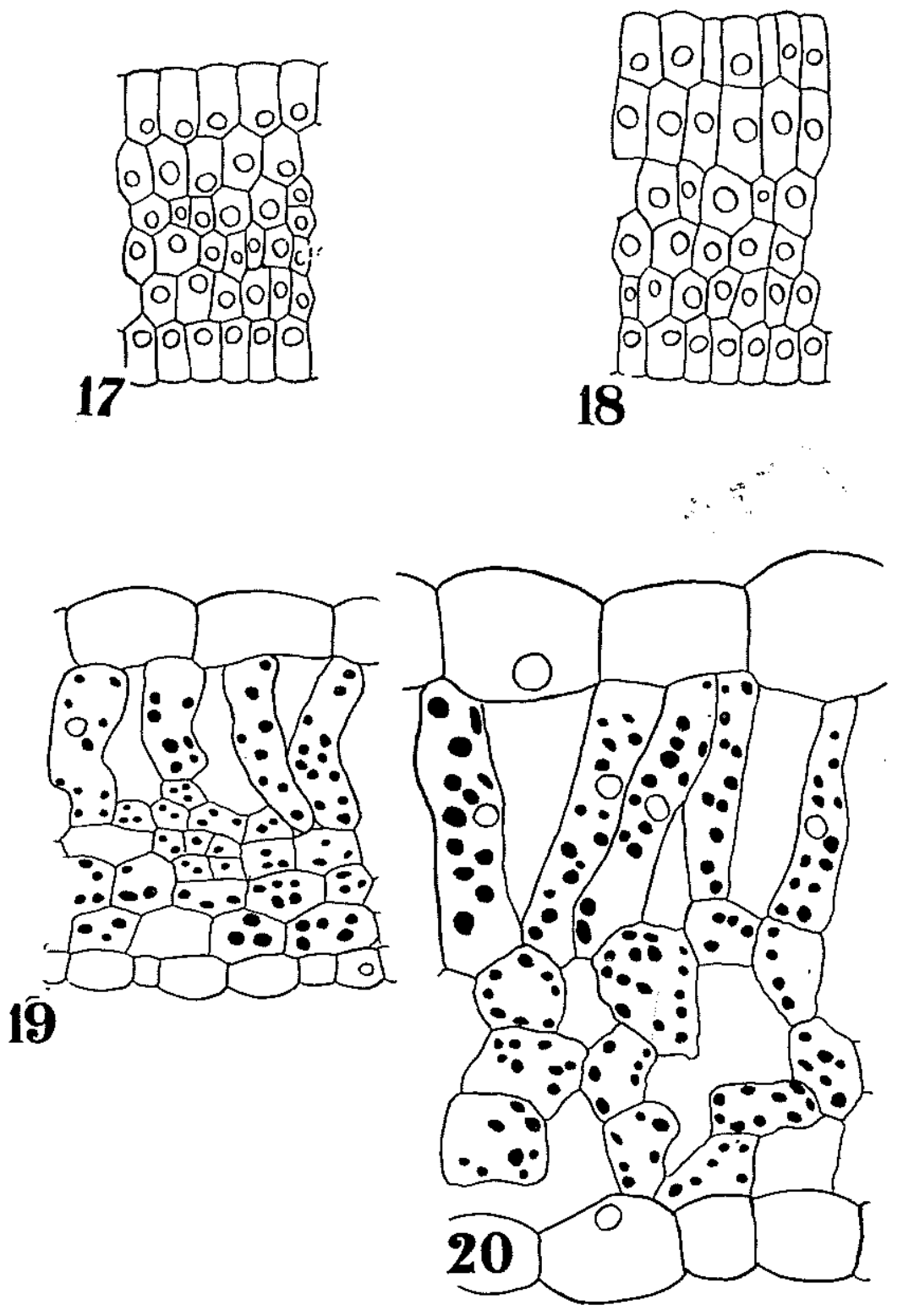


\section{PLATE XIII.}
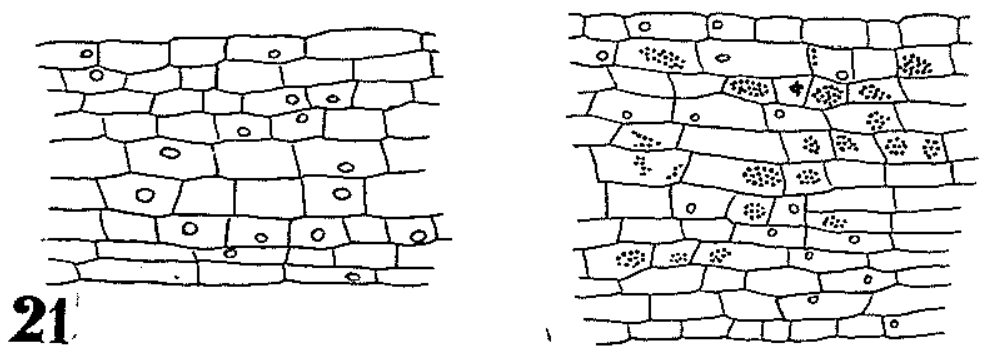

22
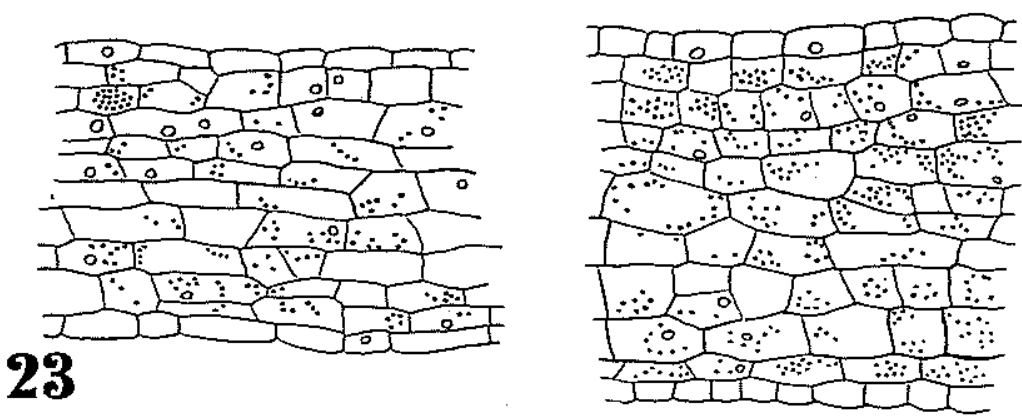

24
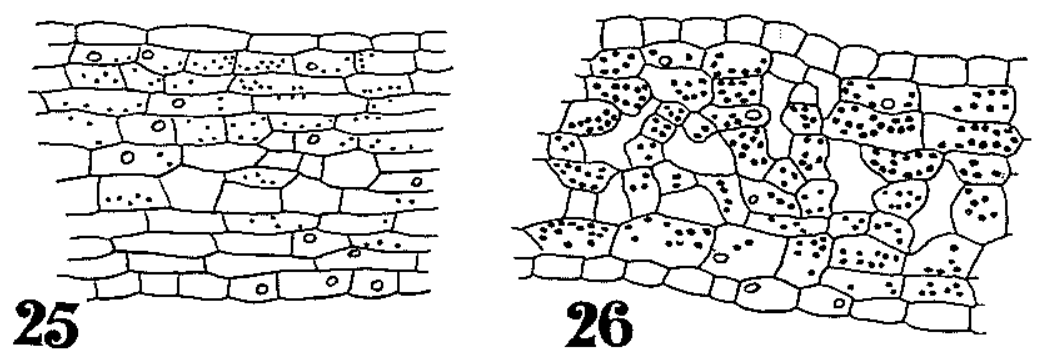